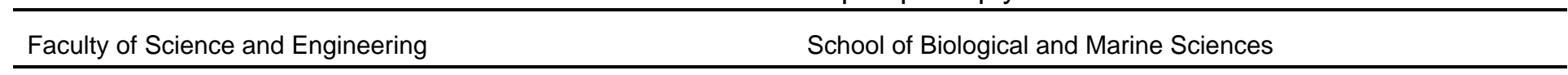

$\longrightarrow$

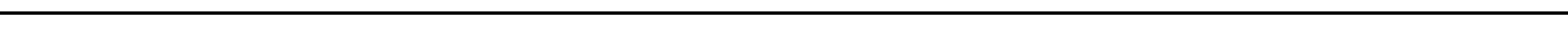





\section{Metadata of the article that will be visualized in OnlineFirst}

\begin{tabular}{|c|c|c|}
\hline \multicolumn{3}{|c|}{ Please note: Images will appear in color online but will be printed in black and white. } \\
\hline ArticleTitle & \multicolumn{2}{|c|}{ 3D surface topography and reflectivity of anisotropic etched silicon micromirrors for BioMEMS } \\
\hline \multicolumn{3}{|l|}{ Article Sub-Title } \\
\hline Article CopyRight & \multicolumn{2}{|c|}{$\begin{array}{l}\text { Springer-Verlag } \\
\text { (This will be the copyright line in the final PDF) }\end{array}$} \\
\hline Journal Name & \multicolumn{2}{|c|}{ Microsystem Technologies } \\
\hline \multirow[t]{8}{*}{ Corresponding Author } & Family Name & Le \\
\hline & \multicolumn{2}{|l|}{ Particle } \\
\hline & Given Name & H. R. \\
\hline & \multicolumn{2}{|l|}{ Suffix } \\
\hline & Division & School of Marine Science and Engineering \\
\hline & Organization & University of Plymouth \\
\hline & Address & Plymouth, UK \\
\hline & Email & huirong.le@plymouth.ac.uk \\
\hline \multirow[t]{8}{*}{ Author } & Family Name & Mackay \\
\hline & \multicolumn{2}{|l|}{ Particle } \\
\hline & Given Name & R. E. \\
\hline & \multicolumn{2}{|l|}{ Suffix } \\
\hline & Division & Centre for Electronic Systems Research, School of Engineering and Design \\
\hline & Organization & Brunel University \\
\hline & Address & UB8 3PH, Uxbridge, Middlesex, UK \\
\hline & Email & ruth.mackay@brunel.ac.uk \\
\hline \multirow[t]{8}{*}{ Author } & Family Name & Lionis \\
\hline & \multicolumn{2}{|l|}{ Particle } \\
\hline & Given Name & N. \\
\hline & \multicolumn{2}{|l|}{ Suffix } \\
\hline & Division & Cass Business School \\
\hline & Organization & City University \\
\hline & Address & London, UK \\
\hline & Email & sinoiljr@hotmail.com \\
\hline & Received & 8 August 2011 \\
\hline \multirow[t]{2}{*}{ Schedule } & \multicolumn{2}{|l|}{ Revised } \\
\hline & Accepted & 28 September 2011 \\
\hline Abstract & \multicolumn{2}{|c|}{$\begin{array}{l}\text { This paper examines wet and dry fabrication of vertical micro-mirrors in (110) silicon for use in an innovative } \\
\text { BioMEMS integrating gripping and micro force sensing functionalities. Wet anisotropic chemical etching in } \\
\text { potassium hydroxide (KOH) and tetramethyl ammonium hydroxide (TMAH) with and without isopropanol } \\
\text { alcohol (IPA) additive was examined. Deep Reactive Ion Etched samples were produced using inductive } \\
\text { coupled process. 3D surface roughness of samples was examined using scanning electron microscope, } \\
\text { interferometric profilometer and atomic force microscopy. An optic fiber displacement sensor was exploited } \\
\text { to measure the reflectivity of uncoated or coated samples with evaporated metallic thin film. The research } \\
\text { aimed to find optimal fabrication technique for fabricating vertical micro-mirrors in polymer based } \\
\text { BioMEMS. TMAH etched silicon samples with surface roughness } R_{\mathrm{a}}=15.1 \mathrm{~nm} \text { showed highest reflectivity }\end{array}$} \\
\hline
\end{tabular}


of all structures fabricated, reflectivity was more than doubled by adding a $10 \mathrm{~nm}$ layer of evaporated aluminum coating.

Footnote Information 


\section{Please ensure you fill out your response to the queries raised below and return this form along with your corrections}

\section{Dear Author}

During the process of typesetting your article, the following queries have arisen. Please check your typeset proof carefully against the queries listed below and mark the necessary changes either directly on the proof/online grid or in the 'Author's response' area provided below

\begin{tabular}{|c|l|}
\hline Query & \multicolumn{1}{|c|}{ Details required } \\
\hline 1. & $\begin{array}{l}\text { 542/1362 ---- Figure 5,8,9 text } \\
\text { illegible and image looks fuzzy }\end{array}$ \\
\hline 2. & $\begin{array}{l}\text { Marx et al. 1997 has been } \\
\text { changed to Marxer et al. 1997, } \\
\text { Graciun et al. 2002 has been } \\
\text { changed to Craciun et al. 2002 so } \\
\text { that the citation matches the list. }\end{array}$ \\
\hline 3. & $\begin{array}{l}\text { Kindly check and confirm the } \\
\text { Affiliations. }\end{array}$ \\
\hline
\end{tabular}




\title{
2 3D surface topography and reflectivity of anisotropic etched silicon micromirrors for BioMEMS
}

\author{
R. E. Mackay • N. Lionis $\cdot$ H. R. Le
}

\begin{abstract}
This paper examines wet and dry fabrication of vertical micro-mirrors in (110) silicon for use in an innovative BioMEMS integrating gripping and micro force sensing functionalities. Wet anisotropic chemical etching in potassium hydroxide $(\mathrm{KOH})$ and tetramethyl ammonium hydroxide (TMAH) with and without isopropanol alcohol (IPA) additive was examined. Deep Reactive Ion Etched samples were produced using inductive coupled process. 3D surface roughness of samples was examined using scanning electron microscope, interferometric profilometer and atomic force microscopy. An optic fiber displacement sensor was exploited to measure the reflectivity of uncoated or coated samples with evaporated metallic thin film. The research aimed to find optimal fabrication technique for fabricating vertical micro-mirrors in polymer based BioMEMS. TMAH etched silicon samples with surface roughness $R_{\mathrm{a}}=15.1 \mathrm{~nm}$ showed highest reflectivity of all structures fabricated, reflectivity was more than doubled by adding a $10 \mathrm{~nm}$ layer of evaporated aluminum coating.
\end{abstract}

R. E. Mackay

Centre for Electronic Systems Research,

School of Engineering and Design, Brunel University,

Uxbridge, Middlesex UB8 3PH, UK

e-mail: ruth.mackay@brunel.ac.uk

\section{N. Lionis}

Cass Business School, City University, London, UK

e-mail: sinoiljr@hotmail.com

H. R. Le ( $($ )

School of Marine Science and Engineering,

University of Plymouth, Plymouth, UK

e-mail: huirong.le@plymouth.ac.uk

\section{Introduction}

MEMS (Micro-electro-mechanical systems) technology was introduced a few decades ago and MOEMS (microopto-electro-mechanical systems) during early 1990s, but it was not until late 1990s when their reliability and effectiveness made them commercially viable. Since then, the market of MEMS and especially MOEMS has experienced an exponential growth in demand as more sectors in industry require their capabilities. The automotive industry is a characteristic example of where MEMS are used extensively nowadays. Mostly in the form of sensors, MEMS are implemented in many parts of a modern automobile. An example is the accelerometers used to detect a collision and inflate an airbag (Matsunaga and Esashi 2002). As the market grows MEMS is being introduced to new fields, one rapidly expanding field is BioMEMS (Biological micro-electro-mechanical systems) (Grayson et al. 2004; Bashir 2004). Currently researchers are working on a project developing polymer micro-grippers with an optical micro force sensor (Fig. 1) (Mackay and Le 2008; Mackay et al. 2011). This is an exciting example to incorporate BioMEMS with MOEMS to fulfill dual requirements of micro object handling and micro force sensing. This project aims to characterise the mechanical properties of the epithelium tissue. The mechanical characterization of tissues will help scientists to understand fundamental cell physiology. With respect to cancer mechanical properties of normal cells could be compared to those of abnormal cells. This could lead to new early diagnostic tools and therapies in the treatment of colon cancer (Suresh 2007). However, the silicon mirror requires through wafer etching to leave a free standing silicon mirror.

Deep etching through silicon wafers has been a problem for many years; the use of these deep etched structures as

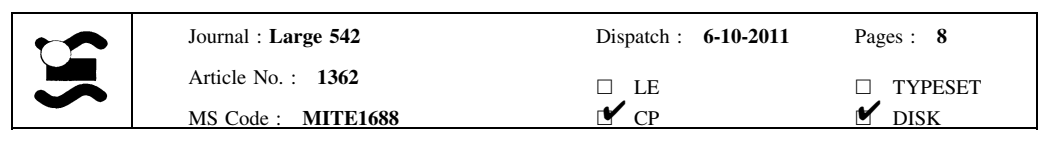




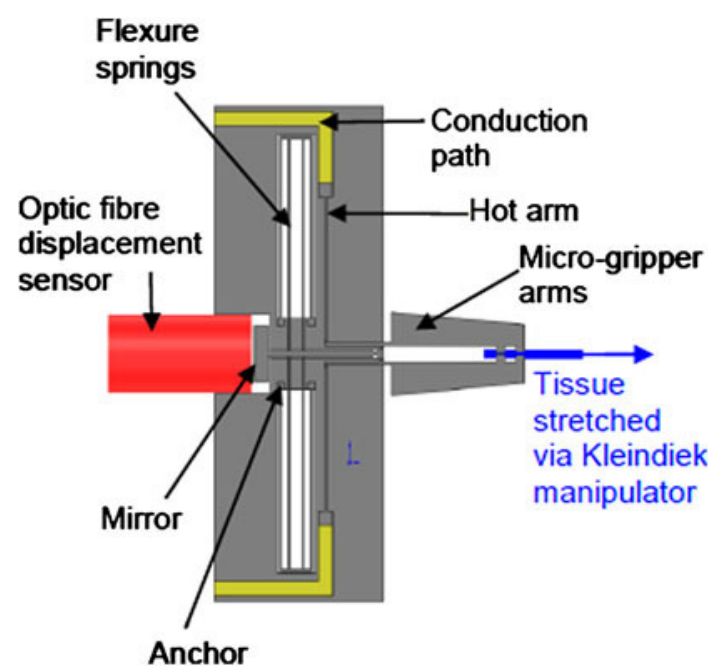

Fig. 1 Design concept for the gripping and force measurement system

mirrors for MOEMS remains a considerable challenge. Through wafer etching must be incorporated in the fabrication of micro-grippers to allow a mirror to be created for displacement sensing. Wet anisotropic etching is the lowest cost and most commonly adopted solution; however geometries are significantly limited by crystal orientation (Agarwal 2007). LIGA can be used to create vertical mirrors; however this requires deep X-ray lithography which is not available in the majority of fabrication units. Deep reactive ion etching allows for complex geometries to be fabricated through wafers, however this generally results in high sidewall roughness although some groups have managed to fabricate mirrors using this etching technique alone (Marxer et al. 1997). A number of groups have amalgamated dry and wet etch techniques to produce complex geometries with smooth sidewalls (Agarwal 2007; Yun et al. 2006). The wafers are orientated and patterned as if for wet etching, however the first step is DRIE followed by a polishing step in a wet etchant to produce $\{111\}$ planes (Price 1973). However, this increases the manufacturing costs.

DRIE can produce non-vertical sidewalls which can have spherical deviation which along with high roughness cause optical losses in MOEMS. DRIE was developed from RIE, a dry isotropic etching process using $\mathrm{SF}_{6}$ radicals to etch silicon. One DRIE technique utilizes two gases to create an anisotropic etch; $\mathrm{SF}_{6}$ is used as the etchant due to fluorine atoms reacting with the silicon substrate, $\mathrm{C}_{4} \mathrm{~F}_{8}$ is used to passivate the sidewalls between each $\mathrm{SF}_{6}$ cycle to allow deep holes to be etched in silicon. The cycles of etching and passivation cause a curtaining effect to occur on the sidewalls of the wafer creating high surface roughness (Craciun et al. 2002). Deep etches cause large defects to occur at the top of the sidewall which has been subjected to a large number of etching and passivation cycles.

Wet anisotropic etching is a lower cost process and requires simple experimental setup which results in high etch rates with smooth walls being fabricated with a high level of anisotropy. Wet chemical etched structures are limited to specific geometries dictated by crystal orientation of the specific silicon wafer type, i.e. (110). Three main types of chemicals are used for anisotropic etching of silicon; alkaline metal hydroxides (i.e. potassium hydroxide $(\mathrm{KOH})$ or sodium hydroxide $(\mathrm{NaOH})$ ) are relatively cheap, non-toxic and result in low roughness sidewalls; diamine based etchants (i.e. ethylenediamine pyrocatecol (EDP)) require complex etch apparatus, have short shelf life and produce highly toxic gases during the reaction with silicon; quaternary ammonium hydroxides (i.e. tetramethyl ammonium hydroxide (TMAH)) has excellent selectivity, is non-toxic, however it is more expensive than alkaline or diamine etchants but can be doped with silicic acid and ammonium persulfate to increase sidewall smoothness (Biswas and Kal 2006). Etching of (110) silicon gives high anisotropy due to the etch rates of the different planes $\{110\}$ etches faster than $\{100\}$ which is faster than $\{111\}$ by a ratio of $400: 200: 1$ at $85^{\circ} \mathrm{C}$ (Kendall 2003).

Isopropanol alcohol (IPA) has been added to alkaline and TMAH etchants to help improve sidewall surface finish. IPA has no active role in the reaction between etchant and silicon (Williams and Muller 1996), however it does reduce the reaction rate, therefore lowering sidewall roughness. Palik et al. (1983) used Raman spectroscopy to understand the reactions occurring during alkaline etching of silicon (Eq. 1)

$\mathrm{Si}+2 \mathrm{H}_{2} \mathrm{O}+2 \mathrm{OH}^{-}=\mathrm{Si}(\mathrm{OH})_{2} \mathrm{O}_{2}^{-}+\mathrm{H}_{2} \mathrm{O}+2 \mathrm{H}_{2}$

The etchant must be mixed mechanically to ensure striation does not occur giving different etch rates throughout the solution (Palik et al. 1983); also if IPA is present this does not readily dissolve in solution, mixing ensures even concentration of IPA throughout the entire solution. Hydrogen bubb $\equiv$ eadily form on the wafer surface, as seen from Eq. 1 Seidel et al. 1990), agitation of the etchant helps remove hydrogen bubbles which can act as a 'pseudo' mask stopping small areas from being etched, increasing surface roughness, due to the formation of hillocks (Yang et al. 2005). Mechanical agitation ensures hydrogen bubbles are removed quickly from the surface of the silicon being etched.

Both DRIE and wet chemical etching rely on a large number of variables to ensure smooth, defect free, vertical sidewalls are obtained. Wet chemical etching depends on type of etchant, concentration of etchant, temperature, mixing rate, additives and alignment to $\{111\}$ plane. DRIE variables include pressure and flow rate of etchant and

\begin{tabular}{|l|lll|}
\hline & Journal : Large $\mathbf{5 4 2}$ & Dispatch : 6-10-2011 & Pages : $\mathbf{8}$ \\
& Article No. : $\mathbf{1 3 6 2}$ & $\square_{\mathrm{LE}}$ & $\square$ \\
MS Code : MITE1688 & $\boldsymbol{V}_{\mathrm{CP}}^{\mathrm{TY}}$ & $\checkmark_{\mathrm{DISK}}$ \\
\hline
\end{tabular}


passivation chemicals, RF power, distribution of reactive fluorine species and concentration and distribution of waste products. Finally wet etching can cause stiction of the envisaged free hanging MEMS structure, which must be taken into account when designing for BioMEMS and MOEMS, whilst DRIE avoids this due to the dry etchants being used.

In total, 42 wet etching experiments were carried out using $\mathrm{KOH}, \mathrm{KOH}+\mathrm{IPA}$, TMAH and TMAH + IPA. Deep reactive ion etched samples were also examined which were etched using inductive coupled plasma process. Sample reflectivity was studied using Philtec D6 fibre optic displacement sensor. Uncoated bare Si samples were tested along with samples coated with a $20 \mathrm{~nm}$ layer of evaporated $\mathrm{Au}-\mathrm{Pd}$ and $10 \mathrm{~nm}$ Al. Samples were examined using light microscopy and SEM. Surface profiling was done using a Dektak (Veeco) surface profiler and Zygo 3D interferometric profilometer.

\section{Experimental procedure}

Silicon wafers (110) p-type (resistivity $1-5 \mathrm{ohm} \mathrm{cm}$ ) single side polished with a $76 \mathrm{~mm}$ diameter and thicknesses of $381 \mu \mathrm{m}$ were used for anisotropic etching experiments. Wafers were thermally oxidized in air to create a $1 \mu \mathrm{m}$ $\mathrm{SiO}_{2}$ insulating layer. The wafer was spin coated with Shipley 1813 photoresist of about $1.2 \mu \mathrm{m}$; this was baked on a hotplate at $115^{\circ} \mathrm{C}$ for $3 \mathrm{~min}$. Two photomask patterns were used throughout the experiments (Fig. 2). The wafer was aligned to the photomask so the $\{111\}$ plane was parallel to the mirror pattern. The wafer was exposed to the mask pattern using an OAI J500 photo aligner. The wafer was exposed for $4 \mathrm{~s}$ and the photoresist developed by immersion in MICROPOSIT MF 321 diluted with deionized $\mathrm{H}_{2} \mathrm{O}$ at a ratio of 1:3 respectively at room temperature for $20 \mathrm{~s}$. The sample was then placed in buffered hydrofluoric acid (BHF) for $7 \mathrm{~min} 30 \mathrm{~s}$ until the oxide was removed leaving bare silicon. Remaining photoresist was removed by rinsing in acetone. The thickness of the oxide layer was verified using a Dektak surface profiler.

Wet etching experiments were carried out in a Teflon beaker (Fig. 3); a magnetic stirrer was placed in the bottom of the beaker to agitate the chemicals as a reaction rate controlled process requires a constant diffusion rate and also avoids stratification of the etchant to maintain even etching across the wafer. A small Teflon guard was placed over the stirrer to avoid collision between this and the silicon wafers being etched. The speed of the stirrer was set to a constant speed of $250 \mathrm{rpm}$ when aqueous solutions of KOH or TMAH were used. However, for solutions with IPA added, the speed was set to $500 \mathrm{rpm}$ to ensure proper mix and distribution of the alcohol into the solution. The beaker

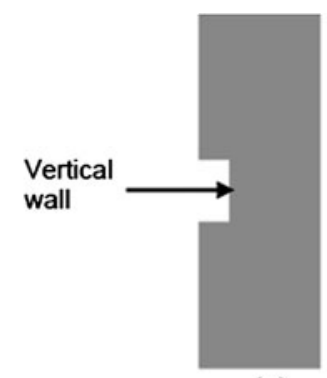

(a)

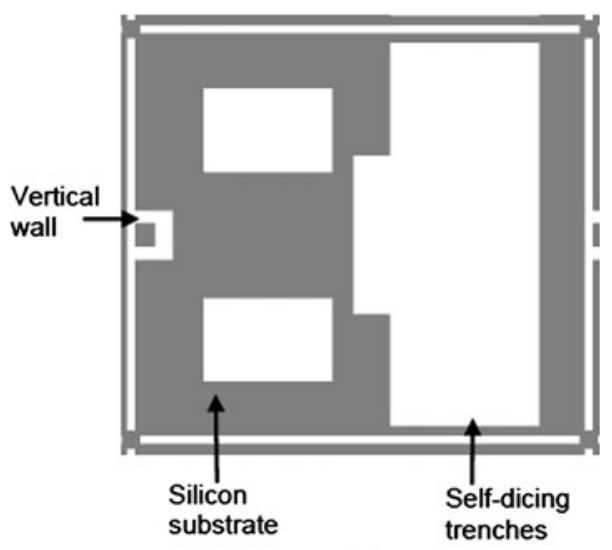

(b)

Fig. 2 Mask patterns used for back etching on (110) silicon wafers a early mask used for initial experiments; b mask designed for polymer micro-gripper system

was placed in a water bath which was placed directly onto a hotplate. The hot plate temperature controller was used in order to set the etching temperature. A probe was placed in the etchant to sense the temperature within the solution and provide feedback to the controller in order for the temperature to remain constant. The hotplate was set at a temperature two times larger than the etching temperature, due to the etchant being in a Teflon beaker immersed in a water bath, which gave a temperature tolerance to the etchant of $\pm 5^{\circ} \mathrm{C}$. Outside of this range the etching temperature either would not be reached or it would be exceeded. Evaporation of the solution was an issue so the plastic beaker was sealed with a cap which featured a small hole for the temperature probe which was placed directly into the solution in order to provide the necessary feedback.

$\mathrm{KOH}$ solutions were made by dissolving $\mathrm{KOH}$ pellets in DI $\mathrm{H}_{2} \mathrm{O}$; this will give $\mathrm{KOH}$ concentration $\pm 5 \%$ due to the absorption of moisture into the KOH pellets (Powell 2001). TMAH solutions were made by mixing $20 \mathrm{wt} \% \mathrm{TMAH}$ solution with DI $\mathrm{H}_{2} \mathrm{O}$. 4\% IPA was added to solutions which contained the alcohol. Wet chemical experiments were carried out using $20 \mathrm{wt} \% \mathrm{KOH}, 25 \mathrm{wt} \% \mathrm{KOH}$, $30 \mathrm{wt} \% \mathrm{KOH}, 25 \mathrm{wt} \% \mathrm{KOH}+\mathrm{IPA}, 30 \mathrm{wt} \% \mathrm{KOH}+$ IPA, $20 \mathrm{wt} \%$ TMAH, $10 \mathrm{wt} \%$ TMAH, $13 \mathrm{wt} \%$ TMAH and $13 \mathrm{wt} \%$ TMAH + IPA.

$\begin{array}{lll}\text { Journal : Large 542 } & \text { Dispatch : 6-10-2011 } & \text { Pages : } 8 \\ \text { Article No. : } \mathbf{1 3 6 2} & \square \text { LE } & \square \text { TYPESET } \\ \text { MS Code : MITE1688 } & \sim_{\text {CP }} & \checkmark \text { DISK }\end{array}$




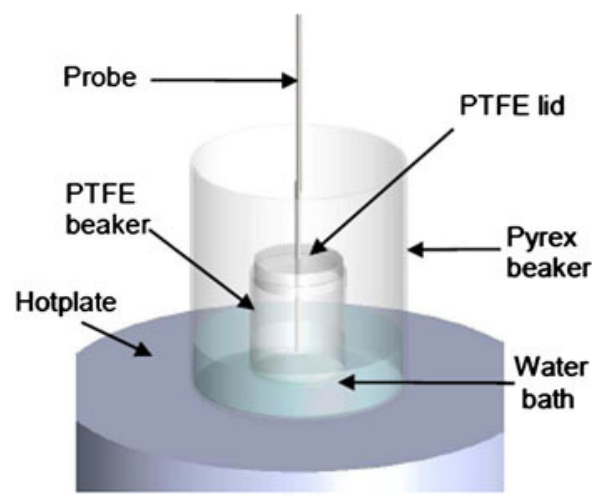

(a)

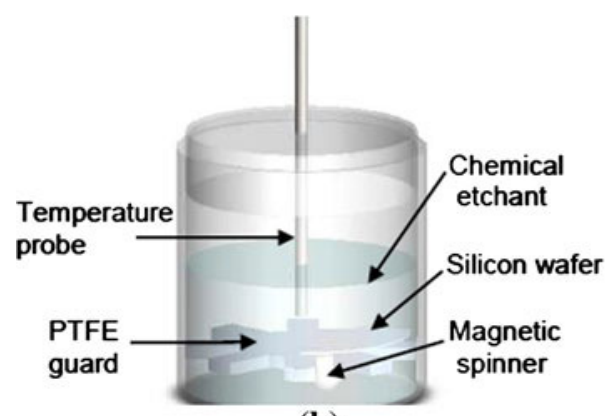

(b)

Fig. 3 Experimental setup for silicon etching experiments a Overview of experimental setup $\mathbf{b}$ teflon beaker for silicon etching

DRIE samples were obtained from the Scottish Microelectronics Centre Edinburgh. These samples were produced on $76 \mathrm{~mm} \mathrm{Si}$ wafers with $200 \mu \mathrm{m}$ thickness. $\mathrm{SF}_{6}$ is used for etching the silicon; this is an anisotropic process however it causes an initial undercut in the silicon. The $\mathrm{C}_{4} \mathrm{~F}_{8}$ is used to passivate the sidewall to stop the area being isotropically etched during the next etching cycle. This helps restrain isotropy but this cannot be completely eliminated as a small amount of undercutting occurs in every etch cycle.

\subsection{Reflectivity tests}

Reflectivity tests were carried out in order to relate surface roughness with optimal reflectivity of samples. Samples tested were polished and unpolished silicon, $30 \mathrm{wt} \%$ $\mathrm{KOH}+\mathrm{IPA}, 25 \mathrm{wt} \% \mathrm{KOH}+\mathrm{IPA}, 13 \mathrm{wt} \%$ TMAH, $13 \mathrm{wt} \%$ TMAH + IPA, 13 wt $\%$ TMAH coated with thermally evaporated Al, DRIE and DRIE then coated with sputtered $\mathrm{Pd} / \mathrm{Au}$.

A 3D micromanipulator by Kleindiek Nanotechnik was used to hold and manipulate samples, whilst a specially designed fibre optic holder was used to ensure the displacement sensor was parallel to the chip (Fig. 4). This allowed for movement of samples in 3 axes with step sizes ranging from 0.25 to $500 \mathrm{~nm}$. Precise alignment between the $\{110\}$ sidewall and fibre optic displacement sensor

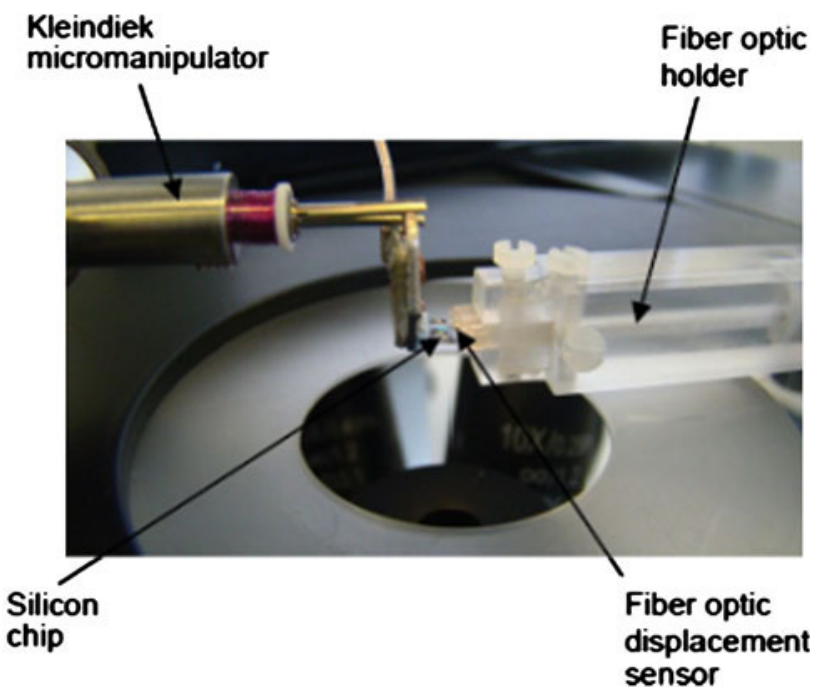

Fig. 4 Reflectivity testing setup

(Philtec D6) is paramount to retrieve accurate results, sidewall thickness is $381 \mu \mathrm{m}$. The fibre optic displacement sensor had wavelength $670 \mathrm{~nm}$.

Static experiments were used to test optimal reflectivity of samples whilst dynamic testing examined the range of voltages that could be acquired when the chip was displaced cyclically over $\pm 288 \mu \mathrm{m}$. Nanocontrol software supplied with the micromanipulator was used to create a macro program to run a series of displacement loops. A Labview program was used to retrieve optimal voltages and displacement voltages.

\section{Results and discussions}

The surface finish of samples was analyzed using a Dektak surface profiler and Zygo interferometric profilometer and Veeco CPii atomic force microscope (AFM). Samples were also examined using both light microscopy to help with sample selection and then scanning electron microscope to examine the microstructure of the etched $\{111\}$ sidewalls.

\subsection{Deep reactive ion etched samples}

Deep reactive ion etched samples showed even etching throughout the majority of the sample. Samples show striated lines due to the process of DRIE (Fig. 5a), cycling etching and passivation. AFM results showed the depth of trenches formed due to the DRIE process (Fig. 5b), the figure shows a $50 \times 50 \mu \mathrm{m}$ area and the resulting curtaining pattern is clearly visible. Etch trenches were measured in the centre of a $\mathrm{Si}$ wafer sidewall showed depths of $\sim 7.5 \mu \mathrm{m}$ which increases surface roughness significantly. DRIE samples varied greatly depending on etch parameters. Average roughness of DRIE samples was found to be $R_{\mathrm{a}}=1,707 \mathrm{~nm}$

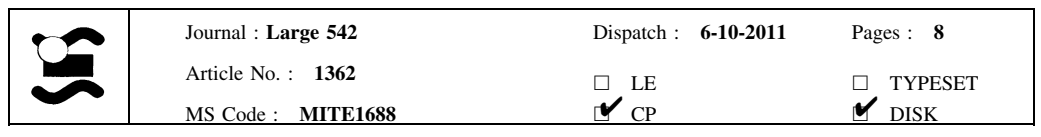




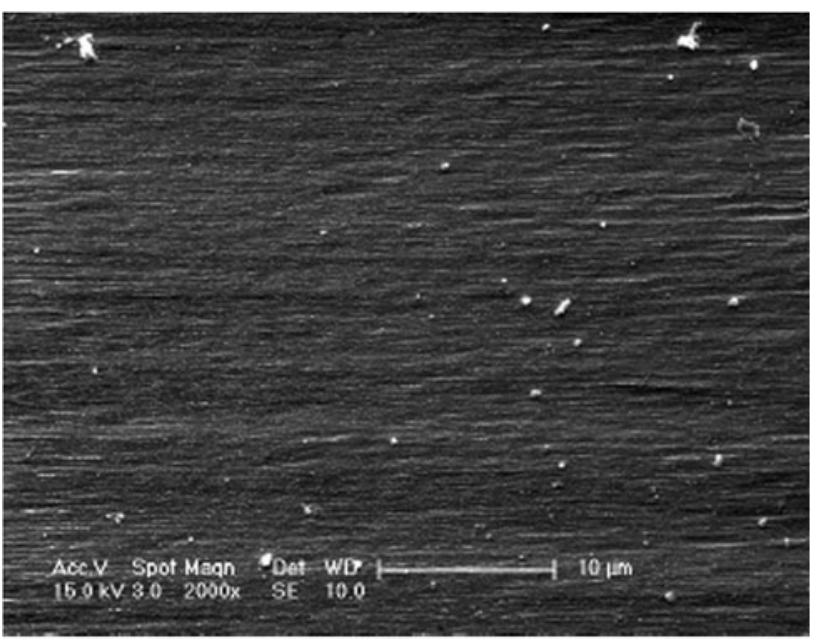

(a)

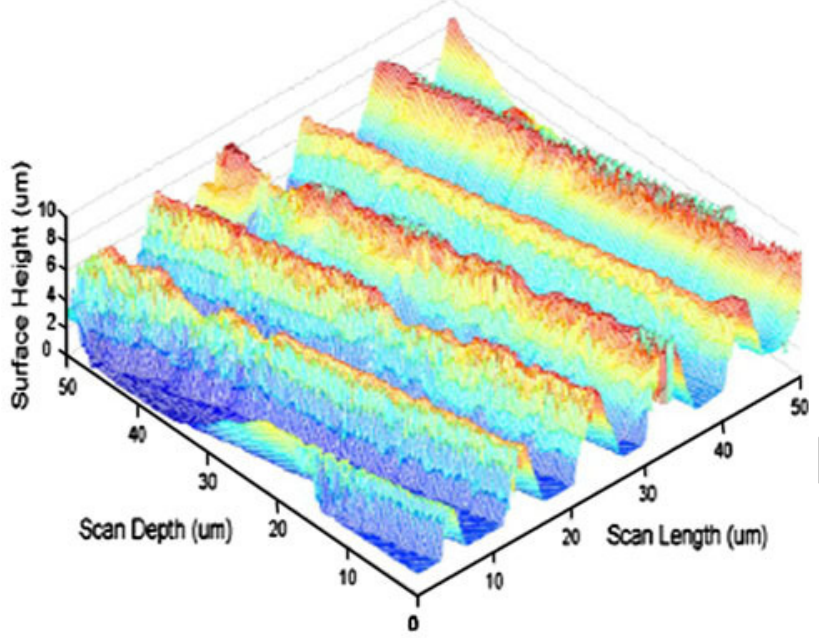

(b)

Fig. 5 Sidewall surface of deep reactive ion etched samples a SEM image and $\mathbf{b}$ AFM scan profile and $\mathrm{rms}=2,027 \mathrm{~nm}$. However the majority of samples showed poor reflectivity. One sample with much lower surface roughness $R_{\mathrm{a}}=533 \mathrm{~nm}$ and $\mathrm{rms}=684 \mathrm{~nm}$ was selected for reflectivity tests. SEM examination of DRIE samples showed large defects occurring at the top of the sidewall where wafers were exposed to thousands of etching and passivation cylces (Fig. 6). These deep trenches could seriously affect reflectivity if they penetrate $>50 \mu \mathrm{m}$ deep into the sidewall. An area of $150 \times 150 \mu \mathrm{m}$ is needed for reflection to the optical displacement sensor. However, the majority of these defects do not penetrate beyond $10 \mu \mathrm{m}$.

\section{$3.2 \mathrm{KOH}$ etched samples}

One of the greatest difficulties the authors faced when etching with $\mathrm{KOH}$ was using $\mathrm{SiO}_{2}$ as a mask for $\mathrm{KOH}$

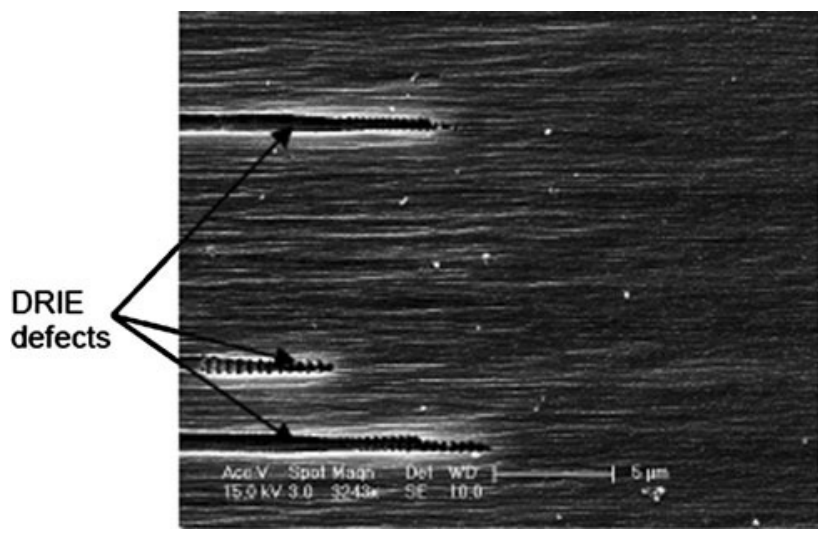

Fig. 6 DRIE defects seen at the top of the wafer where the material is subjected to hundreds of etching and passivation cycles

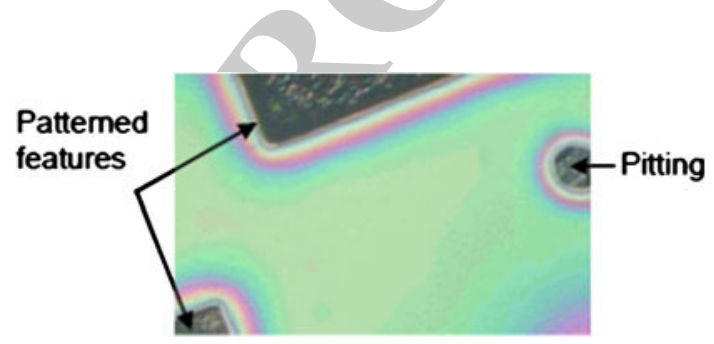

Fig. $7 \mathrm{KOH}$ etched wafers with $1 \mu \mathrm{m} \mathrm{SiO}_{2}$ mask layer

etched samples. Some pitting was seen on the surface of the wafers due to uneven etching of $\mathrm{SiO}_{2}$ across the surface of the wafer, this resulted in masked areas of silicon etching significantly (Fig. 7). $\mathrm{KOH}$ etched samples featured a number of circular trenches forming on the surface of the $\{111\}$ plane when etched at low concentrations $\leq 20 \mathrm{wt} \%$. In order to etch vertical mirrors in (110) silicon $\mathrm{KOH}$ concentrations in the range of $25-35 \mathrm{wt} \%$ were found to be more desirable and fewer circular trenches appeared parallel to the $\{111\}$ plane. Additions of IPA at these concentrations greatly reduced surface roughness; however some pitting was still seen on the surface. Th addition of IPA reduces the etch rate due to changes is surface energy of Si. Figure 8a shows a number of hillocks, which have formed due to hydrogen bubbles acting a 'pseudo' masks throughout the etching process. The AFM results show an uneven surface with significant areas of pitting and the edge of a hillock formed (Fig. 8b).

$\mathrm{KOH}$ samples showed high surface roughness, samples etched in $25 \mathrm{wt} \% \mathrm{KOH}$ at $75^{\circ} \mathrm{C}$ showed $R_{\mathrm{a}}=3,127 \mathrm{~nm}$. $25 \mathrm{wt} \% \mathrm{KOH}+4 \%$ IPA showed lower average roughness of $R_{\mathrm{a}}=1,113 \mathrm{~nm}$ and $\mathrm{rms}=1,316 \mathrm{~nm}$ when etched at $75^{\circ} \mathrm{C}$. Increasing $\mathrm{KOH}$ concentration to $30 \mathrm{wt} \%+4 \%$ IPA decreased surface roughness to $R_{\mathrm{a}}=616 \mathrm{~nm}$ and $\mathrm{rms}=$ $763 \mathrm{~nm}$. Increasing concentrations of $\mathrm{KOH}$ etching solution and addition of IPA significantly decreases the etch rate, slower etch rates show better surface finish due to less

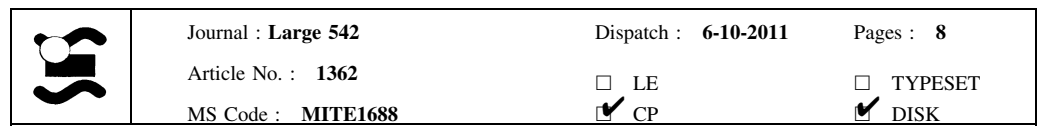




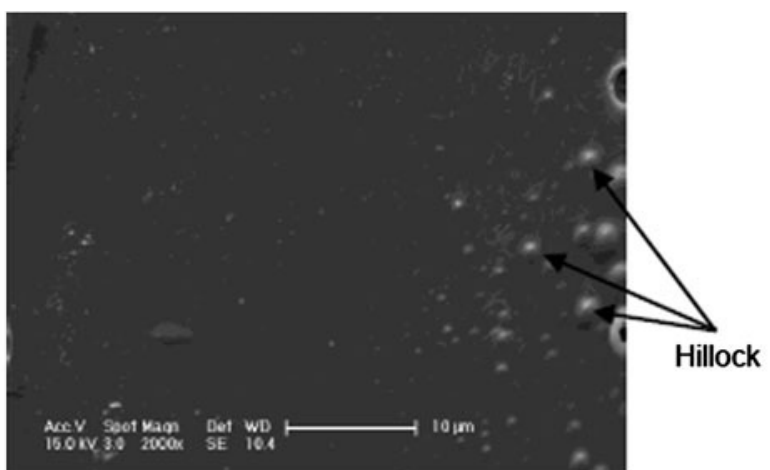

(a)

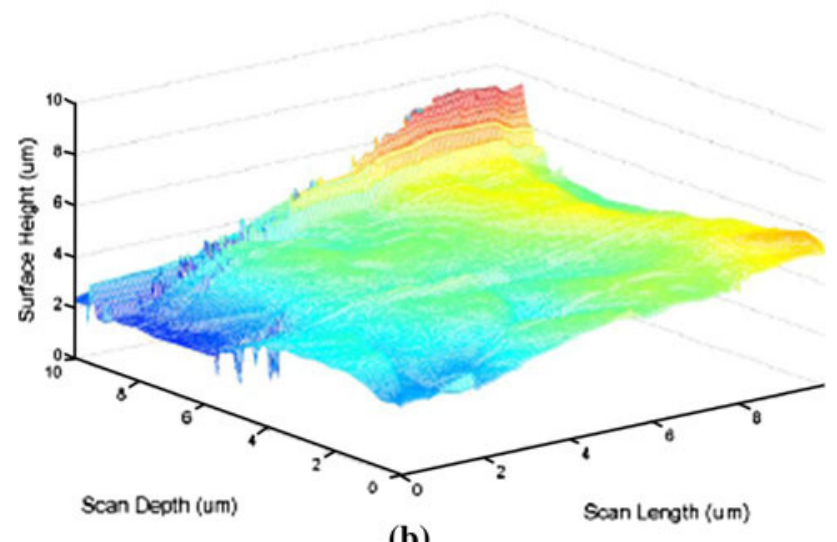

(b)

Fig. 8 SEM image of silicon sidewall etched in $25 \mathrm{wt} \% \mathrm{KOH}+4 \%$ IPA, $70^{\circ} \mathrm{C}, 4 \mathrm{~h} 30 \mathrm{~min}$ a SEM image of vertical mirror b AFM surface profile

defects being formed on the $\mathrm{Si}$ surface. High surface roughness of $\mathrm{KOH}$ samples could be due not only to slight misalignment with $\{111\}$ plane but also depth of etch $>200 \mu \mathrm{m}$ (Sato et al. 1999b).

\subsection{TMAH etched samples}

TMAH showed much better selectivity to the $\mathrm{SiO}_{2}$ mask than $\mathrm{KOH}$. Vertical sidewalls aligned to the $\{111\}$ plane were produced with fewer defects due to this high selectivity. Uniformity of the etched surface was observed to be greater in TMAH than $\mathrm{KOH}$. TMAH samples etched with concentrations of $13 \mathrm{wt} \%$ showed lower surface roughness than those etched at 10 and $20 \mathrm{wt} \%$. The optimum etching temperature was found to be $85^{\circ} \mathrm{C}$.

TMAH samples had a lowest roughness of all samples produced with $R_{\mathrm{a}}=14 \mathrm{~nm}$ and $\mathrm{rms}=20 \mathrm{~nm}$. Figure $9 \mathrm{~b}$ shows an area $10 \times 10 \mu \mathrm{m}$ and the average surface height over this area. Two large hillocks can be seen in this area but their height is $\sim 100 \mathrm{~nm}$.

Samples etched with TMAH only were observed to be less rough than those with the addition of $4 \%$ IPA. Addition of IPA caused striations to occur across the wafer

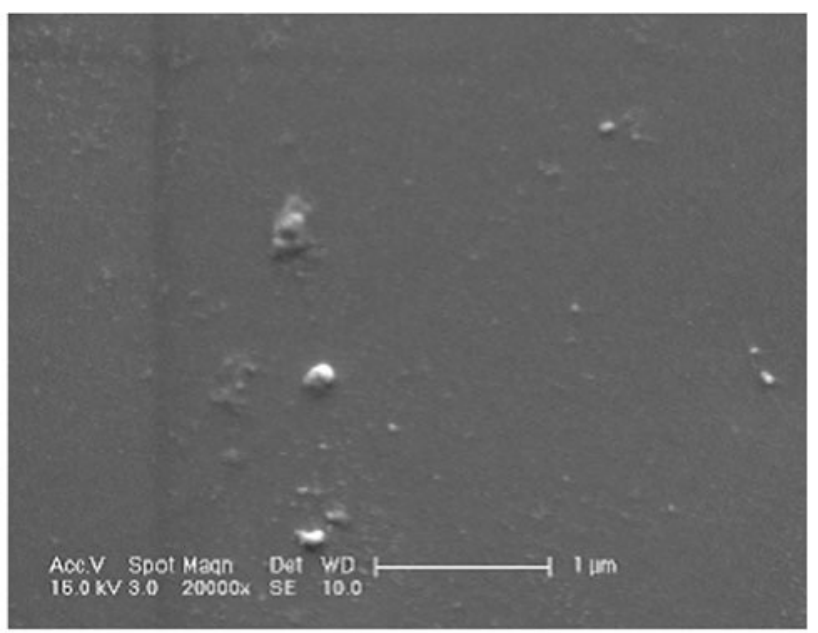

(a)

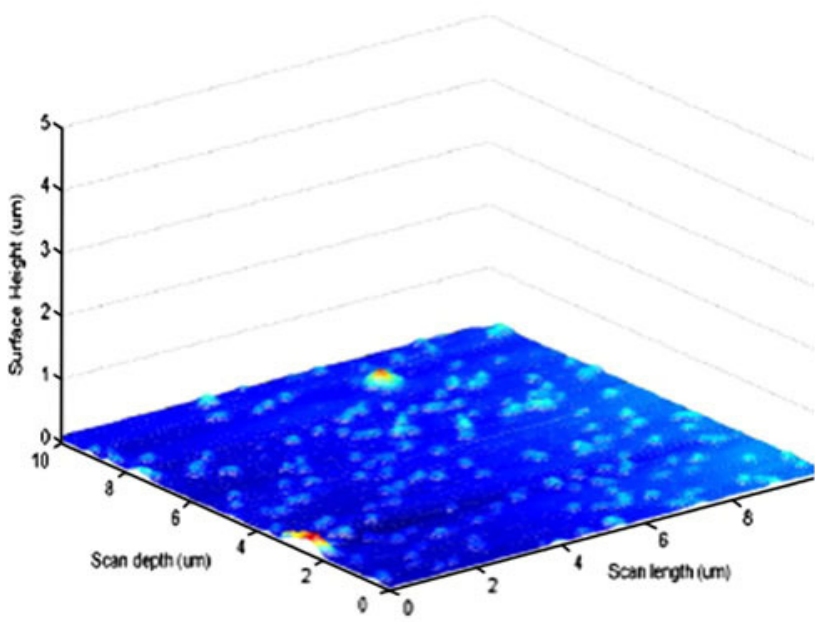

(b)

Fig. 9 AFM surface profile of silicon sidewall etched in $13 \mathrm{wt} \%$ TMAH at $85^{\circ} \mathrm{C}$ a SEM image of vertical mirror b AFM surface profile

increasing surface roughness, however, the addition of IPA did eliminate the formation of hillocks on the $\{111\}$ surface (Fig. 10). Hillocks formed during TMAH etches were significantly smaller and fewer than seen in $\mathrm{KOH}$ etchants.

\subsection{Reflectivity tests}

Optimal alignment was achieved by manipulating the chip when set at a distance of $200 \mu \mathrm{m}$ from the tip of the fiber optic displacement sensor. This distance gives the optimal voltage output from the displacement sensor. The maximum voltages were retrieved during static testing (Table 1). Silicon wafer surface samples of polished silicon and unpolished silicon were used as reference values.

Polished silicon showed the highest static output voltage, $1.66 \mathrm{~V}$, whilst unpolished the lowest; maximum voltage output for the displacement sensor is $5 \mathrm{~V}$. Polished

\begin{tabular}{|l|lll|}
\hline & Journal : Large $\mathbf{5 4 2}$ & Dispatch : $\mathbf{6 - 1 0 - 2 0 1 1}$ & Pages : $\mathbf{8}$ \\
Article No. : $\mathbf{1 3 6 2}$ & $\square_{\mathrm{CP}}^{\mathrm{LE}}$ & $\square_{\text {TISK }}^{\text {TYPEST }}$ \\
\hline
\end{tabular}




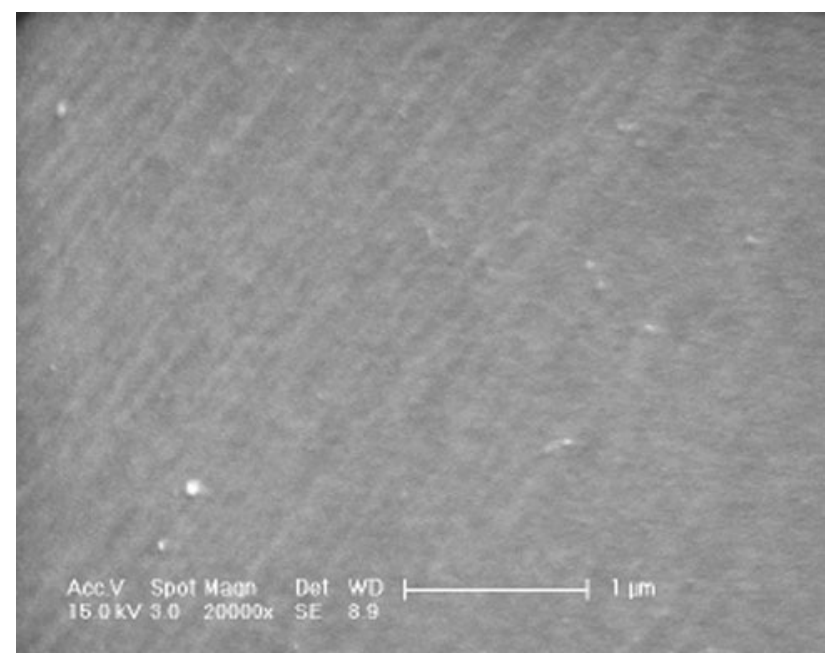

Fig. 10 Samples etched in $13 \mathrm{wt} \%$ TMAH + IPA showed striation and rougher surfaces than those etched with TMAH only

and unpolished silicon samples were much easier to align than sidewall samples as they had a much greater depth $>2 \mathrm{~mm}$ when compared to etched samples which had a depth 200-381 $\mu \mathrm{m}$. TMAH showed lowest surface roughness and highest maximum voltage, $0.83 \mathrm{~V}$ during static tests, this increased significantly to $2.48 \mathrm{~V}$ once coated with $10 \mathrm{~nm}$ Al. DRIE samples tested were those with the lowest roughness $\left(R_{\mathrm{a}}=533 \mathrm{~nm}\right)$. DRIE samples showed output voltage of $0.72 \mathrm{~V}$ which increased to $1.12 \mathrm{~V}$ whe the Pd-Au coating was sputtered on the surface. TMA$\mathrm{H}+$ IPA samples showed much lower static output voltage of $0.35 \mathrm{~V}$ due to the striations scattering light away from the fiber optic sensor. Samples etched in $30 \mathrm{wt} \%$ $\mathrm{KOH}+\mathrm{IPA}$ gave an output voltage of $0.24 \mathrm{~V}$ whilst $25 \mathrm{wt} \% \mathrm{KOH}+$ IPA gave an output voltage of $0.04 \mathrm{~V}$ showing slower etch rates increase reflectivity. However due to defects in $\mathrm{KOH}$ etched silicon arising because of poor masking, reflectivity is lower than DRIE samples. Samples etched with $\mathrm{KOH}$ only could not be tested as

Table 1 Summary of optimal voltage outputs and voltage variation for $\pm 288 \mu \mathrm{m}$ of displacement

\begin{tabular}{lll}
\hline Etching technique/solution & $\begin{array}{l}\text { Optimal } \\
\text { voltage }(\mathrm{V})\end{array}$ & $\begin{array}{l}\text { Voltage } \\
\text { variation (V) }\end{array}$ \\
\hline Polished silicon & 1.66 & 0.26 \\
DRIE metalized & 1.12 & 0.1 \\
$13 \mathrm{wt} \%$ TMAH metalized & 2.48 & 0.07 \\
$13 \mathrm{wt} \%$ TMAH & 0.83 & 0.11 \\
DRIE & 0.72 & 0.17 \\
$13 \mathrm{wt} \% \mathrm{TMAH}+\mathrm{IPA}$ & 0.35 & 0.05 \\
$30 \mathrm{wt} \% \mathrm{KOH}+\mathrm{IPA}$ & 0.24 & 0.05 \\
Unpolished silicon & 0.15 & - \\
$25 \mathrm{wt} \% \mathrm{KOH}+\mathrm{IPA}$ & 0.04 & - \\
\hline
\end{tabular}

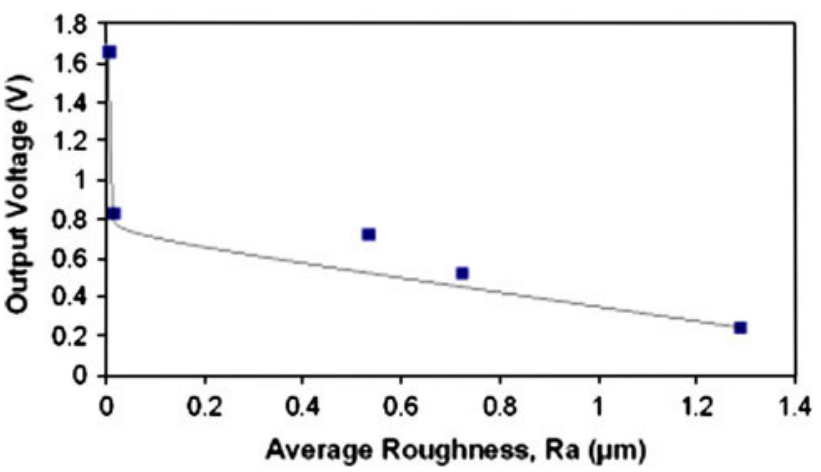

Fig. 11 Static reflectivity tests showing optical sensor output voltage vs average roughness of silicon sidewall mirror

samples did not reflect enough light to produce an output voltage. Static output voltages were related to average roughness $\left(R_{\mathrm{a}}\right)$ measurements (Fig. 11). Polished silicon $\left(R_{\mathrm{a}}=5 \mathrm{~nm}\right)$ shows significantly higher output voltage when compared to TMAH samples $\left(R_{\mathrm{a}}=14 \mathrm{~nm}\right)$, it is believed this is due to the small area being tested and difficulty in aligning the $200 \mu \mathrm{m}$ thick sample to the tip of the optic fiber. Sato et al. found orientation dependence of etching differs be $\equiv$ the two wet etchants, within the current experiments TMAH was found to be easier to align to $\{111\}$ orientation (Sato et al. 1999a). It can be seen that DRIE samples $\left(R_{\mathrm{a}}=533 \mathrm{~nm}\right)$ with lower roughness than $\mathrm{KOH}+$ IPA samples $(567 \mathrm{~nm})$ showed higher output voltage than the slightly rougher $\mathrm{KOH}+$ IPA samples. Addition of highly reflective metals (i.e. Au-Pd), sputtered onto the silicon sidewalls greatly increased static voltage output. Au-Pd has excellent reflectivity of near $100 \%$ for the wavelength of light $(690 \mathrm{~nm})$ being reflected. Al has slightly lower reflectance around $95 \%$ for the specific displacement sensor however it is much lower cost. $\mathrm{Si}$ showed lowest reflectivity and is highly dependent on surface roughness (Hashim and Salih 2005).

Displacement experiments were carried out using the Kleindiek micromanipulator, the range of output voltage difference for displacement of $566 \mu \mathrm{m}$ is shown in Table 1 . Results were poorer than expected but it is believed this is due to parasitic motion in the micromanipulator, resulting in rotation of samples, this resulted in misalignment of the wafer to the fiber optic sensor.

\section{Conclusions}

Etching of silicon in multifunctional BioMEMS represents a complex procedure due to the number of variables and the associated outcomes of each. Fabrication of vertical mirror surfaces via anisotropic deep etching through wafers for BioMEMS is achievable by controlling the etch rate and extraction of gaseous products from the etchant. One

\begin{tabular}{lll} 
Journal : Large 542 & Dispatch : 6-10-2011 & Pages : 8 \\
Article No. : $\mathbf{1 3 6 2}$ & $\square$ LE & $\square$ TYPESET \\
MS Code : $\quad$ MITE1688 & $\boldsymbol{\sim}_{\text {CP }}$ & $\checkmark$ DISK \\
\hline
\end{tabular}


obvious limit of anisotropic etching is the limit of the pattern to the crystal orientation of (110) wafers, it is impossible to produce rectangular structures and trapezoids are formed in the structure; however it is proved possible to orientate the wafer so the mirror is present and perfectly aligned to the $\{111\}$ plane. A new method was developed to examine the reflectivity of micro-engineered surface using optic fiber displacement sensor and 3D piezoelectric manipulator.

The results show that concentration of both $\mathrm{KOH}$ and TMAH is an important factor to produce optimal surfaces. Generally higher percentages of $\mathrm{KOH}$ result in smoother walls, here the optimal is $30 \mathrm{wt} \%$, this slows down the etch rate resulting in smoother walls when examined using SEM. KOH must be used with the addition of IPA, to reduce surface energy of $\mathrm{Si}$ and cause fewer hillocks to be formed, samples etched in $\mathrm{KOH}$ only could not be used as vertical silicon mirrors. The addition of IPA to TMAH solutions resulted in rougher, striated surfaces being formed. For TMAH, the optimal etchant concentration was found to be $13 \mathrm{wt} \%$. Temperature of etchant also results in variability of smooth sidewalls, for $\mathrm{KOH}+\mathrm{IPA}$ lower temperatures, $\leq 70^{\circ} \mathrm{C}$ resulted in optimal smoothness, the lowering of temperature helps slow the etch rate. For TMAH etchants, the optimal was found to be $85^{\circ} \mathrm{C}$.

The argument by previous authors that TMAH etches can result in smoother sidewalls than $\mathrm{KOH}$ etched samples, was proved. TMAH showed good results with the lowest $R_{\mathrm{a}}$ recorded and highest output of uncoated micro-samples. It was also found that IPA did not improve the surface quality when TMAH was used. $\mathrm{KOH}+\mathrm{IPA}$ showed higher roughness due to the formation of sizable hillocks and significant pitting in the $\mathrm{SiO}_{2}$ mask. If $\mathrm{KOH}$ is to be used to form vertical sidewalls $\mathrm{SiN}$ must be employed as the mask.

DRIE samples showed significantly higher surface roughness than TMAH but performed well during reflectivity results. Uncoated samples gave a reasonable static output voltage from the fiber optic displacement sensor. Coated samples of DRIE and TMAH gave the best overall reflectivity results, as expected.

Acknowledgments Financial support of EPSRC and IDB Technologies Ltd. towards a PhD Studentship for R.E.M. is acknowledged. The authors would like to express gratitude to Dr Camelia Dunare at the SMC, University of Edinburgh for providing DRIE samples; Dr Robert Keatch for constructive discussions; Martin Kierans for help provided using the SEM and Dr Gary Callon for general support in the cleanroom at University of Dundee. Finally, Mark Rainer for help provided using the Zygo interferometer at the University of Cambridge.

\section{References}

Agarwal R (2007) Fabrication of vertical mirrors using plasma etch and KOH: IPA polishing. J Micromech Microeng 17(1):26-35

Bashir R (2004) BioMEMS: state-of-the-art in detection, opportunities and prospects. Adv Drug Deliv Rev 56(11):1565-1586

Biswas K, Kal S (2006) Etch characteristics of KOH, TMAH and dual doped TMAH for bulk micromachining of silicon. Microelectron J 37(6):519-525

Craciun G, Blauw MA, Van Der Drift E, Sarro PM, French PJ (2002) Temperature influence on etching deep holes with $\mathrm{SF}_{6} / \mathrm{O}_{2}$ cryogenic plasma. J Micromech Microeng 12(4):390-394

Grayson ACR, Shawgo RS, Johnson AM, Flynn NT, Li Y, Cima MJ (2004) A BioMEMS review: MEMS technology for physiologically integrated devices. Proc IEEE 92(1):6-21

Hashim MR, Salih KQ (2005) Optical properties of treated and untreated monocrystalline $\mathrm{p}-\mathrm{Si}<1 \quad 1 \quad 1>, \quad \mathrm{p}-\mathrm{Si}<1 \quad 0 \quad 0>$, $\mathrm{n}-\mathrm{Si}<1 \quad 1 \quad 1>$ and $\mathrm{n}-\mathrm{Si}<1 \quad 0 \quad 0>$ wafers in the visible region at room temperature. Microelectron Eng 81(2-4):243-250

Kendall DL (2003) Vertical Etching of silicon at very high aspect ratios. Annu Rev Mat Sci 9(1):373-403

Mackay RE, Le HR (2008) Development of micro-tweezers for tissue micro-manipulation. In: Proceedings of the 2nd International Conference on Bioinformatics and Biomedical Engineering, pp 1551-1554, Shanghai, China, 2008

Mackay RE, Le HR, Keatch RP (2011) Design optimization and fabrication of SU-8 based electro-thermal micro-grippers. $\mathrm{J}$ Micro/Nano Mechatron 6(1-2):13-22

Marxer C, Thio C, Gretillat MA, de Rooij NF, Battig R, Anthamatten $\mathrm{O}$ (1997) Vertical mirrors fabricated by deep reactive ion etching for fiber-optic switching applications. J Microelectromech Syst 6(3):277-285

Matsunaga T, Esashi M (2002) Acceleration switch with extended holding time using squeeze film effect for side airbag systems. Sens Actuators A Phys 100(1):10-17

Palik ED, Gray HF, Klein PB (1983) A Raman study of etching silicon in aqueous KOH. J Electrochem Soc 130(4):956-959

Powell O (2001) Anisotropic etching of 100 and 110 planes in (100) silicon. J Micromech Microeng 11(3):217-220

Price JB (1973) Anisotropic etching of silicon with $\mathrm{KOH}-\mathrm{H}_{2} \mathrm{O}-$ isopropyl alcohol. In: Huff HR, Burgess RR (eds) Semiconductor silicon. Princeton, NJ, pp 339-353

Sato K, Shikidaa M, Yamashiroa T, Tsunekawaa M, Itob S (1999a) Roughening of single-crystal silicon surface etched by $\mathrm{KOH}$ water solution. Sens Actuators A 73(1-2):122-130

Sato K, Shikidaa M, Yamashiroa T, Asaumi K, Iriye Y, Yamamoto M (1999b) Anisotropic etching rates of single-crystal silicon for TMAH water solution as a function of crystallographic orientation. Sens Actuators A 73(1-2):131-137

Seidel H, Csepregi L, Heuberger A, Baumgartel H (1990) Anisotropic etching of crystalline silicon in alkaline solutions. J Electrochem Soc 137(11):3612-3626

Suresh S (2007) Biomechanics and biophysics of cancer cells. Acta Biomater 3(4):413-438

Williams KR, Muller RS (1996) Etch rates for micromachining processing. J Microelectromech Syst 5(4):256-269

Yang CR, Chen PY, Chiou YC, Lee RT (2005) Effects of mechanical agitation and surfactant additive on silicon anisotropic etching in alkaline KOH solution. Sens Actuators A 119(1):263-270

Yun SS, You SK, Lee JH (2006) Fabrication of vertical optical plane using DRIE and KOH crystalline etching of (llll 110$)$ silicon wafer. Sens Actuators A 128(2):387-394
460

461

462

463

464

465

466

467

468

469

470

471

472

473

474

475

$\begin{array}{lll}\text { Journal : Large 542 } & \text { Dispatch : 6-10-2011 } & \text { Pages : } 8 \\ \text { Article No. : } \mathbf{1 3 6 2} & \square \text { LE } & \square \text { TYPESET } \\ \text { MS Code : MITE1688 } & \sim_{\text {CP }} & \sim_{\text {DISK }}\end{array}$

